\title{
Leaching of ${ }^{60} \mathrm{Co}$ and ${ }^{137} \mathrm{Cs}$ from spent ion exchange resins in cement-bentonite clay matrix
}

\author{
I B PLECAS*, R S PAVLOVIC and S D PAVLOVIC \\ VINCA Institute of Nuclear Sciences, P.O. Box 522, 11001 Belgrade, Serbia and Montenegro
}

MS received 22 August 2003; revised 7 October 2003

\begin{abstract}
The leaching rate of ${ }^{60} \mathrm{Co}$ and ${ }^{137} \mathrm{Cs}$ from the spent cation exchange resins in cement-bentonite matrix has been studied. The solidification matrix was a standard Portland cement mixed with $290-350\left(\mathrm{~kg} / \mathrm{m}^{3}\right)$ spent cation exchange resins, with or without $2-5 \%$ of bentonite clay. The leaching rates from the cementbentonite matrix for ${ }^{60} \mathrm{Co}:(4,2-7,0) \times 10^{-5}(\mathrm{~cm} / \mathrm{d})$ and ${ }^{137} \mathrm{Cs}:(3,2-6,6) \times 10^{-4}(\mathrm{~cm} / \mathrm{d})$, after 125 days were measured. From the leaching data the apparent diffusivity of cobalt and cesium in cement-bentonite clay matrix with a waste load of $290-350\left(\mathrm{~kg} / \mathrm{m}^{3}\right)$ spent cation exchange resins, was measured for ${ }^{60} \mathrm{Co}:(1,1-4,0) \times$ $10^{-6}\left(\mathrm{~cm}^{2} / \mathrm{d}\right)$ and ${ }^{137} \mathrm{Cs}:(0,5-2,6) \times 10^{-4}\left(\mathrm{~cm}^{2} / \mathrm{d}\right)$, after 125 days. The results presented in this paper are part of the results obtained in a 20 -year mortar and concrete testing project which will influence the design of radioactive waste management for a future Serbian radioactive waste disposal centre.
\end{abstract}

Keywords. Cement; radioactive waste; composite; waste management.

\section{Introduction}

Ion exchange may be used most successfully for the removal of radioactive ions from dilute solutions. This process produces deionized water, as the radioactive ions are removed together with non radioactive ones. Ion exchangers are resins that are polymers with cross-linking (connections between long carbon chains in a polymer). The resin has active groups in the form of electrically charged sites. At these sites ions of opposite charge are attracted but may be replaced by other ions depending on their relative concentrations and affinities for the sites. Spent cation exchange resins containing ${ }^{60} \mathrm{Co}$ and ${ }^{137} \mathrm{Cs}$ represent a major portion of the solid radioactive waste in nuclear technology.

Cement is used as a solidification material for the storage of intermediate-level radioactive waste. However, the retention of radionuclides, especially cesium, in the cement matrix is negligible. The sorption of cesium on cement is low and diffusivity of cesium in the hydrated cement is high (Andersson et al 1981; Atkinson and Nickerson 1988). Only when the cement is mixed with a material having a significant sorption capacity, normally bead or powdered ion exchange resins, the leachability of cesium and cobalt from the cement matrix is low enough to be acceptable (Hespe 1971; Plecas et al 1985, 1990, 1992).

The objectives of immobilization are to convert the waste into forms which are leach resistant so that the rele-

\footnotetext{
*Author for correspondence
}

ase of radionuclides will be slow even though flowing water may contact them and mechanically, physically and chemically stable for handling, transport and disposal.

Although cement has several unfavourable characteristics as a solidifying material, i.e. low volume reduction and relatively high leachability, it possesses many practical advantages: good mechanical characteristics, low cost, easy operation and radiation and thermal stability. It is generally assumed that the cement leachability of ${ }^{137} \mathrm{Cs}$ and other radionuclides can be reduced by adding minerals like bentonite, vermiculite and zeolite. Whereas zeolite was excluded for economy and availability reasons, out of the above and other minerals, a natural bentonite is especially preferable in our leaching tests (Torstenfeld and Hedin 1988).

\section{Materials and methods}

The cement specimens were prepared from construction cement which is basically a standard Portland cement. The cement was mixed with saturated wet cation exchange resins (100 g of dry resins $+100 \mathrm{~g}$ of water containing ${ }^{60} \mathrm{Co}$ and $\left.{ }^{137} \mathrm{Cs}\right)$ and bentonite clay $\left(63 \% \mathrm{SiO}_{2} ; 18 \% \mathrm{Al}_{2} \mathrm{O}_{3}\right.$; $4 \% \mathrm{Fe}_{2} \mathrm{O}_{3} ; 2,6 \% \mathrm{MgO}$ and $\left.3,3 \% \mathrm{CaO}\right)$. The mixtures were cast into $50 \mathrm{~mm}$ diameter cylindrical molds with a height of $50 \mathrm{~mm}$, which were then sealed and cured for 28 days prior to the leaching experiments (Plecas et al 1985, 1990).

More than 100 different formulations of mortar form were examined to optimize their mechanical and sorption properties. In this paper we discuss eight representative 
formulations. Grout composition formulas are shown in table 1.

\section{Experimental}

Samples for leachability determination were prepared according to the IAEA standard procedure (Hespe 1971). Leachant was exchanged and analysed for radioactivity after 1, 2, 3, 4, 5, 6, 7 days, and thereafter every week for 1 month and from there on every month, until 125th day. After each leaching period the radioactivity in the leachant was measured using EG\&G-ORTEC spectrometry system and software. The volume of the leachant in every leaching period was $200 \mathrm{ml}$.

Preliminary testing of grout compressive strength was done using a classical method which is practiced in civil engineering. Cube shaped grout samples of $10 \times 10 \times$ $10 \mathrm{~cm}$ were used. Compressive strength was expressed in $\mathrm{MPa}$.

\section{Mathematical treatment of data}

The results are expressed by incremental leaching rate, $R_{\mathrm{n}}(\mathrm{cm} / \mathrm{d})$, as

$$
R_{\mathrm{n}}=\frac{\sum a_{\mathrm{n}}}{A_{0}} \frac{V}{S} \frac{1}{\sum t}(\mathrm{~cm} / \mathrm{d}),
$$

where $a_{\mathrm{n}}$ is the radioactivity of leached constituent during each leaching interval $(\mathrm{Bq}), A_{0}$ the specific radioactivity initially present in the specimen $(\mathrm{Bq}), S$ the exposed surface area of the specimen $\left(\mathrm{cm}^{2}\right), V$ the sample volume $\left(\mathrm{cm}^{3}\right)$ and $t$ the duration of leaching period (d).
The apparent diffusivity, $D_{\mathrm{e}}$, is calculated from

$$
D_{\mathrm{e}}=\frac{\pi}{4} m^{2} \frac{V^{2}}{S^{2}}\left(\mathrm{~cm}^{2} / \mathrm{d}\right),
$$

where $m$ is the slope of the straight line from a plot of $\sum a_{\mathrm{n}} / A_{0}$ vs $\sqrt{ } \sum t_{\mathrm{n}}\left(d^{-1 / 2}\right)$.

\section{Results and discusion}

The results of the leaching tests of immobilized spent cation exchange resins are given as the incremental leaching rate, $R_{\mathrm{n}}(\mathrm{cm} / \mathrm{d})$, after 125 days. Although there are experimental results before 125 th day, which are not given in this paper, leaching rate of ${ }^{60} \mathrm{Co}$ and ${ }^{137} \mathrm{Cs}$ does not indicate any significant difference in leaching.

Table 2 gives the results of incremental leach rate, $R_{\mathrm{n}}$ $(\mathrm{cm} / \mathrm{d})$ and apparent diffusivity, $D_{\mathrm{e}}\left(\mathrm{cm}^{2} / \mathrm{d}\right)$ after 125 days, keeping in view the decay of radionuclides $\left({ }^{60} \mathrm{Co}\right.$ and $\left.{ }^{137} \mathrm{Cs}\right)$. A significant difference in leaching and in apparent diffusivity of ${ }^{60} \mathrm{Co}$ and ${ }^{137} \mathrm{Cs}$ in immobilized spent cation exchange resins, was observed and give us a possibility to extrapolate leachability in next 20 years and more. Analysis of the results presented in table 2 shows that the values are very similar to the literature data and proves that cement-bentonite matrix permits secure preservation of radionuclides for more than 300 years. Results presented in this paper are part of the results obtained in 20-year grout and concrete testing project which will influence the design of a radioactive waste management for a future Serbian radioactive waste storing centre. Testing of mechanical characteristics of cement matrix was performed with each of the eight samples. Table 3 gives compressive strength of 8 grout compositions in $\mathrm{MPa}$.

Table 1. Grout composition (calculated as grams for $1000 \mathrm{~cm}^{3}$ of mixtures).

\begin{tabular}{lrrrrrrrr}
\hline & \multicolumn{8}{c}{ Formula } \\
\cline { 2 - 8 } Materials (g) & \multicolumn{1}{c}{$M_{1}$} & \multicolumn{1}{c}{$M_{2}$} & \multicolumn{1}{c}{$M_{3}$} & \multicolumn{1}{c}{$M_{4}$} & \multicolumn{1}{c}{$M_{5}$} & $M_{6}$ & $M_{7}$ & $M_{8}$ \\
\hline Cation exchange resins & 350 & 350 & 350 & 350 & 290 & 290 & 290 & 290 \\
Portland cement & 1270 & 1280 & 1315 & 1270 & 1340 & 1335 & 1380 & 1340 \\
Water & 280 & 275 & 260 & 258 & 308 & 320 & 300 & 308 \\
Bentonite clay & 26 & 38 & 15 & 20 & 54 & 66 & 0 & 0 \\
\hline
\end{tabular}

Initial activity, $A_{0}=8,0 \cdot 10^{7} \mathrm{~Bq} /$ per sample $\left({ }^{60} \mathrm{Co}\right.$ and $\left.{ }^{137} \mathrm{Cs}\right)$.

Table 2. Incremental leach rate, $R_{\mathrm{n}}(\mathrm{cm} / \mathrm{d})$ and apparent diffusivity, $D_{\mathrm{e}}\left(\mathrm{cm}^{2} / \mathrm{d}\right)$ of ${ }^{60} \mathrm{Co}$ and ${ }^{137} \mathrm{Cs}$

\begin{tabular}{|c|c|c|c|c|c|c|c|c|}
\hline \multirow[b]{2}{*}{ Radionuclide } & \multicolumn{8}{|c|}{ Formula } \\
\hline & $M_{1}$ & $M_{2}$ & $M_{3}$ & $M_{4}$ & $M_{5}$ & $M_{6}$ & $M_{7}$ & $M_{8}$ \\
\hline$R_{\mathrm{n}}{ }^{60} \mathrm{Co} \times 10^{5}$ & 4,70 & 4,65 & 5,50 & 6,80 & 4,20 & 4,40 & 7,00 & 6,70 \\
\hline$R_{\mathrm{n}}{ }^{137} \mathrm{Cs} \times 10^{4}$ & 5,20 & 5,00 & 5,10 & 5,40 & 3,20 & 3,60 & 6,50 & 6,60 \\
\hline$D_{\mathrm{e}}{ }^{60} \mathrm{Co} \times 10^{6}$ & 1,90 & 1,90 & 1,80 & 1,90 & 1,10 & 1,20 & 4,00 & 4,00 \\
\hline$D_{\mathrm{e}}{ }^{137} \mathrm{Cs} \times 10^{5}$ & 14,00 & 1,50 & 7,00 & 7,50 & 5,20 & 5,20 & 24,00 & 26,00 \\
\hline
\end{tabular}
after 125 days. 
Table 3. Compressive strength, $M(\mathrm{MPa})$.

\begin{tabular}{lccccccc}
\hline \multicolumn{7}{c}{ Formula } \\
\hline$M_{1}$ & $M_{2}$ & $M_{3}$ & $M_{4}$ & $M_{5}$ & $M_{6}$ & $M_{7}$ & $M_{8}$ \\
28,5 & 29,0 & 29,0 & 29,5 & 24,0 & 23,4 & 25,0 & 24,0 \\
\hline
\end{tabular}

\section{Acknowledgement}

The work was supported by the Ministry of Science, Technologies and Development of the Republic Serbia under Contract No. 1985 (Research and Development of processes and materials for treatment of radioactive and hazardous waste and environmental hazard assessment).

\section{References}

Andersson K, Torstenfelt B and Allard B 1981 Diffusion of cesium in concrete, in Scientific basis for nuclear waste management (New York: Plenum Press) 3 235-242

Atkinson A and Nickerson A 1988 Nucl. Technol. 81100 Hespe E D 1971 Atomic Energy Rev. 9195

Plecas I, Mihajlovic L and Kostadinovic A 1985 Radioactive Waste Management and the Nuclear Fuel Cycle 6161

Plecas I, Drljaca J, Peric A, Kostadinovic A and Glodic S 1990 Radioactive Waste Management and the Nuclear Fuel Cycle 14195

Plecas I, Peric A, Kostadinovic A, Drljaca J and Glodic S 1992 Cem. Concr. Res. 22937

Torstenfeld B and Hedin G 1988 Scientific Basis for Nuclear Waste Management 127495 